\title{
Standardized ileal digestible valine requirement for laying hens
}

\author{
J.W. Spek \\ Wageningen Livestock Research
}

CVB Documentation report nr. 73

June 2018

Wageningen Livestock Research

P.O. Box 338

$6700 \mathrm{AH}$ Wageningen

The Netherlands 


\section{(c) Federatie Nederlandse Diervoederketen 2017}

No part of this edition may be copied, photocopied, reproduced, translated or reduced to any electronic medium or machine-readable form, in whole or in part, without specific written permission of the Federatie Nederlandse Diervoederketen (info@diervoederketen.nl).

All copyrights and database rights with respect to this publication are expressly reserved. Nothing in this publication may be reproduced, copied, retrieved, made public or re-used or made available in any way whatsoever to third parties by way of printing, photocopying, microfilm or in any other way unless the Federatie Nederlandse Diervoederketen has given express written permission to do so. This publication has been compiled with great care; however, the Federatie Nederlandse Diervoederketen and Wageningen Livestock Research cannot be held liable in any way for the consequences of using the information in this publication. 


\section{Preface}

In 2017 a new Table has been introduced called; Table 'Standardized ileal digestibility of amino acids in feedstuffs for poultry' and has been described in the CVB Documentation report $\mathrm{nr}$. 61. As a feed evaluation system has two pillars - the supply of nutrients by the diet on the one hand and the requirement for these nutrients by the animals on the other hand (both expressed in the same units) - it was also necessary to also update and express the amino acid requirements on a standardized ileal digestibility (SID) basis.

Therefore a large meta-analysis dataset was constructed from studies in which amino acid requirements in laying hens were estimated. The SID amino acid concentrations of the diets used in these studies were recalculated based on the new CVB SID amino acid Table presented in CVB documentation report $\mathrm{nr} .61$ and the requirement for SID valine was subsequently estimated. The results of this meta-analysis for standardized ileal digestible valine (SID-VAL) requirement are presented in the present CVB Documentation report. Compared to the former CVB apparent faecal digestible VAL recommendation for laying hens described in CVB Documentation report nr. 18 and published in 1996 the present established SID-VAL amino acid recommendations for laying hens are:

1. Based on a study with modern laying hen types in the period $1990-2017$

2. Based on standardized ileal digestible amino acid values in feedstuffs instead of apparent faecal digestible amino acid values.

The in this report estimated requirements of SID-VAL will be incorporated in the Dutch CVB Tabellenboek Veevoeding Pluimvee 2018 and in the English version CVB Table Poultry Nutrition 2018.

This study was guided and assessed by the Technical Committee of CVB and the Ad hoc group 'SID amino acid requirements for laying hens'

Wageningen, June 2018

J.W. Spek 


\section{Members of the Technical Committee of the CVB}
M. Rijnen (chair)
J. Fledderus
B. Boswerger
A. Dijkslag
H. van Laar
K. Geerse
D. van Manen
J. van der Staak
H. Korterink
A. van de Ven
C. van Vuure
G. van Duinkerken

J.W. Spek
Nederlandse Vereniging Diervoederindustrie (Nevedi)

Nederlandse Vereniging Diervoederindustrie (Nevedi)

Nederlandse Vereniging Diervoederindustrie (Nevedi)

Nederlandse Vereniging Diervoederindustrie (Nevedi)

Nederlandse Vereniging Diervoederindustrie (Nevedi)

Nederlandse Vereniging Diervoederindustrie (Nevedi)

Overleggroep Producenten Natte Veevoeders (OPNV)

Land- en Tuinbouworganisatie Nederland (LTO)

Nederlandse Vereniging van Handelaren in Stro, Fourages en

Aanverwante Producten (HISFA)

Nederlandse Vereniging Diervoederindustrie (Nevedi)

MVO, ketenorganisatie voor oliën en vetten

Wageningen Livestock Research, Dept. Animal Nutrition, Wageningen

Wageningen Livestock Research, Dept. Animal Nutrition, Wageningen

\section{Members of the Ad hoc group 'SID amino acid requirements for laying hens'}
A. Dijkslag
M. van Erp
K. Geerse
A. de Ruijter
J.W. Spek
B. Swart

ForFarmers, Lochem

De Heus, Ede

Trouw Nutrition, Amersfoort

De Hoop, Zelhem

Wageningen Livestock Research, Wageningen

Agrifirm, Apeldoorn 


\section{Contents}

Table of Contents

Page

Preface

3

Members of the Technical Committee of the CVB ........................................................ 4

Members of the Ad hoc group 'SID amino acid requirements for laying hens' ..................... 4

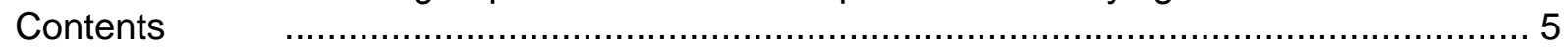

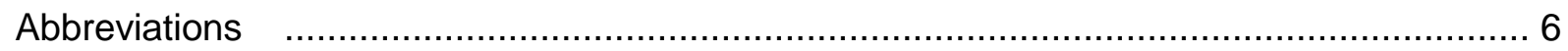

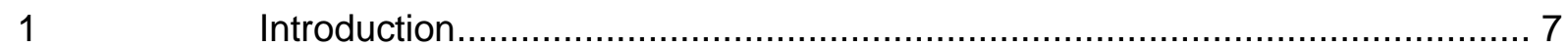

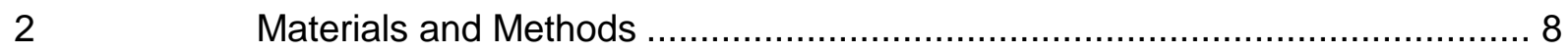

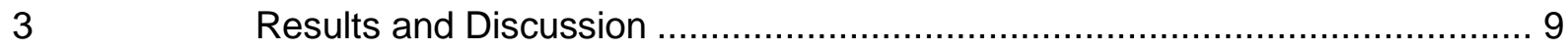

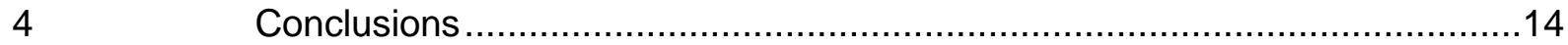

List of studies included in the meta-analysis ..............................................................15

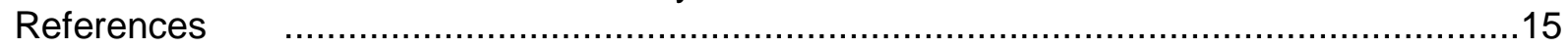

Appendix A. Relationship between dietary SID-VAL supply and performance parameters FCR and EM for the various titration trials including the estimated SID-VAL requirements based on the quadratic broken-line model.............................16

Appendix B. SID-VAL model estimates for minimum FCR and maximum EM ...................19 


\section{Abbreviations}

$\begin{array}{ll}\text { AA } & \text { Amino acids } \\ \text { AFD } & \text { Apparent faecal digestible } \\ \text { ARG } & \text { Arginine } \\ \text { BW } & \text { Body weight } \\ \text { BWG } & \text { Body weight gain } \\ \text { CP } & \text { Crude protein } \\ \text { CYS } & \text { Cysteine } \\ \text { EM } & \text { Egg mass } \\ \text { FCR } & \text { Feed conversion ratio } \\ \text { ILE } & \text { Isoleucine } \\ \text { LYS } & \text { Lysine } \\ \text { Max } & \text { Maximum value } \\ \text { ME } & \text { Metabolic energy } \\ \text { MElh } & \text { Metabolic energy for laying hens } \\ \text { MET } & \text { Methionine } \\ \text { Min } & \text { Minimum value } \\ \text { M+C } & \text { Methionine plus Cysteine } \\ \text { N } & \text { Number } \\ \text { R } & \text { Coefficient of determination } \\ \text { Req. } & \text { Requirement } \\ \text { SID } & \text { Standardized ileal tract digestible } \\ \text { Std. Dev. } & \text { Standard deviation } \\ \text { Std. Err. } & \text { Standard error } \\ \text { THR } & \text { Threonine } \\ \text { TRP } & \text { Tryptophan } \\ \text { VAL } & \text { Valine } \\ \text { \%CV } & \text { Coefficient of variation } \\ & \end{array}$




\section{Introduction}

In 2012 a large meta-analysis was carried out by van Krimpen and others in order to determine the dietary requirements for standardized ileal tract digestible (SID) amino acids (AA) for laying hens. This study resulted in a report published by van Krimpen et al. (2015). Before the start of this meta-analysis another large meta-analysis was carried out in order to determine the SID-AA levels for the various feed ingredients. This meta-analysis resulted in a CVB table with SID-AA concentrations for the various feed ingredients and this Table was used by van Krimpen et al. (2015) in order to recalculate the dietary SID-AA levels for the individual AA titration studies in order to estimate AA requirements. However, in 2017 this CVB Table has been updated with new data published in the years between 2012 and 2017 as there were questions about the SID cysteine digestibility value for soybean meal. As a result, not only the SID-AA values for soybean meal have been updated but also for other feedstuffs. As a consequence it was necessary to recalculate all the diets used in the AA titration studies that van Krimpen et al. (2015) used to determine AA-requirements. In this study the results of estimated dietary SID valine (SID-VAL) requirements are presented based on the new Table values as presented in CVB documentation report nr. 61 . 


\section{Materials and Methods}

VAL requirement studies were selected from literature $(1990-2017)$ in which the dietary VAL content was varied by means of addition of graded levels of dietary synthetic VAL. Furthermore, performance characteristics such as egg mass (EM: $g / d / h e n)$ and feed conversion ratio (FCR; $g$ feed : $g$ egg mass) had to be recorded and information with respect to dietary composition and age of the laying hens had to be provided in the studies. The apparent faecal digestible (AFD) non-test-AA : AFD-LYS ratios needed to be at least $90 \%$ of the CVB (2012) requirement level and the basal AFD-VAL : AFD-LYS ratio needed to be at least 15\% below the CVB (2012) AFD-VAL : AFD-LYS requirement level.

Requirements were estimated using a quadratic broken-line model as described below. This model was adopted from a publication of Robbins et al. (2006) and was used for estimation of SID-LYS requirements in LYS titration studies with laying hens as well as described in CVB Documentation report nr. 69.

The quadratic broken-line model is as follows:

If $(\operatorname{SID}-V A L(\%)<R)$ then $E M$ or $F C R=L+U \times(R-S I D-V A L)^{\wedge}$;

Else $E M$ or $F C R=L+U \times 0$;

Where:

$\mathrm{L}=$ plateau value for $\mathrm{EM}$ or FCR

$\mathrm{R}=$ break-point value for SID-VAL (\%)

$\mathrm{U}=$ slope value, representing the increase in EM or decrease in FCR per unit increase in dietary SID-VAL. 


\section{Results and Discussion}

In Table 1. Some characteristics of the studies included in the meta-analysis is given. The dataset consisted of 1 study with in total 3 trials and 24 observations.

In Appendix A for each titration trial the relationship between dietary SID-VAL (\%) and FCR and between dietary SID-VAL (\%) and EM is presented graphically together with the estimated SID-VAL requirements for the quadratic broken-line model.

In Appendix B the estimated quadratic broken-line model parameters for each titration trial is given.

In two cases (for trials 2 and 3 ) also model estimates are provided in case the treatments with the highest two dietary SID-VAL concentrations were removed as it was expected that for this trial this would significant affect model estimates of $R$ (or requirement estimates for SID-VAL). The model predictions for these two trials were the two highest dietary SID-VAL treatments were removed prior to fitting the model are shown with the letter "a" (i.e. trial 2 becomes trial $2 \mathrm{a}$ ).

In Table 2 the average estimated optimal SID-VAL concentrations and SID-VAL intake statistics for maximum EM minimum FCR are presented.

Table 2. Estimated optimal SID-VAL requirements (\% and daily intake) for maximum egg mass (EM) based on trials 1, 2a and 3a.

\begin{tabular}{|l|l|l|r|r|r|r|r|}
\hline & Parameter & $\mathbf{N}$ & Mean & Std. Dev. & Min. & Max & \%CV \\
\hline \multirow{2}{*}{ SID-VAL (\%) } & EM & 3 & 0.546 & 0.0548 & 0.511 & 0.610 & 10.0 \\
\cline { 2 - 7 } & FCR & 3 & 0.497 & 0.0152 & 0.479 & 0.507 & 3.1 \\
\hline \multirow{2}{*}{$\begin{array}{l}\text { SID-VAL intake } \\
\text { (mg/d) }\end{array}$} & EM & 3 & 603 & 84.1 & 542 & 699 & 14.0 \\
\cline { 2 - 7 } & FCR & 3 & 540 & 20.6 & 523 & 562 & 3.8 \\
\hline \multirow{2}{*}{$\begin{array}{l}\text { SID-VAL intake per EM (mg/g) } \\
\text { g of }\end{array}$} & EM & 3 & 10.8 & 0.93 & 10.1 & 11.8 & 8.7 \\
\cline { 2 - 8 } $\begin{array}{l}\text { SID-VAL:SID-LYS } \\
\text { ratio }\end{array}$ & FCR & 3 & 9.8 & 0.43 & 9.3 & 10.1 & 4.4 \\
\cline { 2 - 8 } & FCR & 3 & 95 & 14.1 & 82 & 110 & 14.8 \\
\hline \multirow{2}{*}{$\begin{array}{l}\text { SID-VAL:SID-LYS } \\
\text { ratio* }\end{array}$} & EM & 3 & 86 & 5.7 & 80 & 92 & 6.6 \\
\cline { 2 - 8 } & FCR & 3 & 95 & 13.8 & 83 & 110 & 14.5 \\
\hline
\end{tabular}

${ }^{\star}$ This ratio is calculated using formula [F8] from CVB Documentation report nr. 69 to predict SID-LYS requirement. In case the formula [F8] resulted in a lower SID-LYS requirement than the observed SIDLYS intake at which maximum EM or minimum FCR was estimated, then this formula was used to calculate the SID-VAL:SID-LYS ratio, otherwise the observed SID-LYS intake at which maximum EM or minimum FCR was estimated was used. 
Table 1. Summary of the total dataset

\begin{tabular}{|c|c|c|c|c|c|c|c|c|c|c|c|c|}
\hline Study & Trial & Breed & $\begin{array}{r}\text { Starting } \\
\text { Age } \\
\text { (weeks) }\end{array}$ & $\begin{array}{r}\text { Duration of } \\
\text { experiment } \\
\text { (weeks) }\end{array}$ & $\begin{array}{l}\text { Dietary } \\
\text { CP (\%) }\end{array}$ & $\begin{array}{r}\text { Max } \\
\text { obs. } \\
\text { rate of } \\
\text { lay (\%) } \\
\end{array}$ & $\begin{array}{c}\text { Max } \\
\text { obs. } \\
\text { egg } \\
\text { mass }\end{array}$ & $\begin{array}{r}\text { Max } \\
\text { obs. } \\
\text { feed } \\
\text { intake } \\
\end{array}$ & $\begin{array}{c}\text { Min } \\
\text { SID- } \\
\text { VAL } \\
(\%) \\
\end{array}$ & $\begin{array}{c}\text { Max } \\
\text { SID- } \\
\text { VAL } \\
(\%) \\
\end{array}$ & $\begin{array}{r}\text { Max. } \\
\text { FCR } \\
\text { minus } \\
\text { Min. FCR } \\
\end{array}$ & $\begin{array}{r}\text { Max. egg } \\
\text { mass } \\
\text { minus Min. } \\
\text { egg mass }\end{array}$ \\
\hline \multirow{3}{*}{ Peganova and Eder (2002) } & 1 & Lohmann Brown & 25 & 8 & 11.9 & 94 & 53 & 106 & 0.327 & 0.747 & 0.62 & 25 \\
\hline & 2 & Lohmann Brown & 24 & 9 & 14.2 & 99 & 59 & 115 & 0.429 & 1.279 & 0.15 & 5.9 \\
\hline & 3 & Lohmann Brown & 46 & 9 & 14.2 & 91 & 57 & 117 & 0.429 & 1.279 & 0.12 & 3.5 \\
\hline
\end{tabular}


The requirement for dietary SID-VAL for maximum EM production was also estimated directly on the data from Peganova and Eder (2002) after excluding the observations beyond the maximum response level (Fig. 1). Furthermore, the requirement for dietary SID-VAL for minimum FCR was also estimated directly on the data from Peganova and Eder (2002) after excluding the observations beyond the minimum FCR observation (Fig. 2)

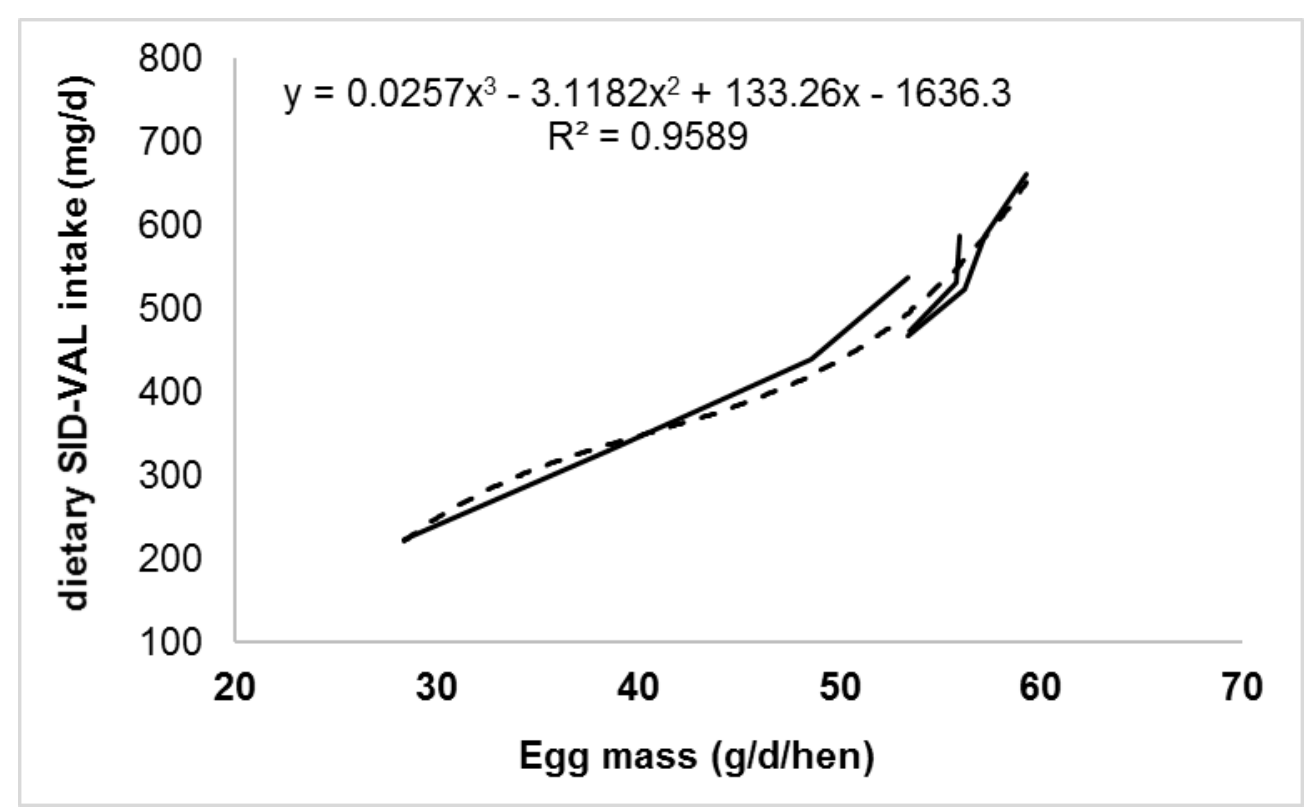

Figure 1. Relationship between dietary SID-VAL intake (mg/d/hen) and egg mass produced $(\mathrm{g} / \mathrm{d} / \mathrm{hen})$. Dashed curve was fitted through the pooled dataset of observations after excluding the observations beyond the maximum response level of egg mass.

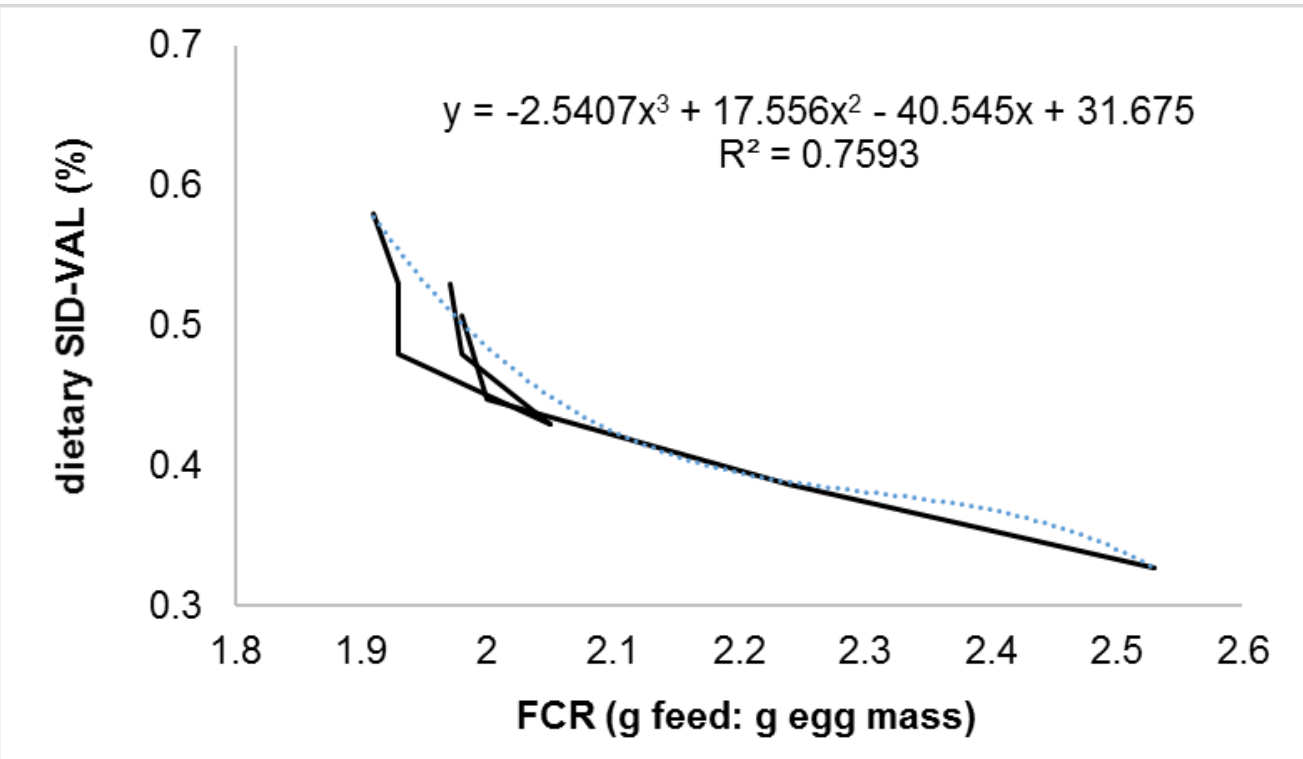

Figure 2. Relationship between dietary SID-VAL (\%) and FCR ( $\mathrm{g}$ feed/g egg mass). Dashed curve was fitted through the pooled dataset of observations after excluding the observations beyond the minimum response level of FCR.

In Table 3 the estimated SID-VAL requirements are given based on an average estimated SID-VAL requirement of $10.8 \mathrm{mg}$ SID-VAL per $\mathrm{g}$ of EM for maximum EM production as shown in Table 2. 
Table 3. Estimated optimal SID-VAL requirements for maximum EM expressed in $\mathrm{mg} / \mathrm{d}$ and as a percentage of the diet for maximum EM at various egg production rates based on a SIDVAL requirement of $10.8 \mathrm{mg}$ SID-VAL per $\mathrm{g}$ of EM for maximum EM production as shown in Table 2. The calculated feed intake required for an average egg weight of $60 \mathrm{~g}$ and at egg production rates of 90 and $95 \%$ are based on the assumptions presented as a footnote $\left(^{*}\right)$ underneath this Table.

\begin{tabular}{|c|c|c|c|c|c|c|c|c|c|c|}
\hline \multirow[b]{3}{*}{ BW (kg) } & \multicolumn{2}{|c|}{$\begin{array}{r}\text { Feed intake } \\
(\mathrm{g} / \mathrm{d})\end{array}$} & \multicolumn{2}{|c|}{$\begin{array}{r}\text { Egg mass } \\
(\mathrm{g} / \mathrm{d})\end{array}$} & \multicolumn{2}{|c|}{$\begin{array}{r}\text { SID-VAL } \\
(\mathrm{mg} / \mathrm{d})\end{array}$} & \multicolumn{2}{|c|}{$\begin{array}{r}\text { Dietary SID- } \\
\text { VAL (\%) }\end{array}$} & \multicolumn{2}{|c|}{$\begin{array}{l}\text { SID-VAL:SID- } \\
\text { LYS ratio** }\end{array}$} \\
\hline & \multicolumn{10}{|c|}{ Egg production rate $(\%)$} \\
\hline & 90 & 95 & 90 & 95 & 90 & 95 & 90 & 95 & 90 & 95 \\
\hline 1.5 & 112 & 115 & 54 & 57 & 583 & 616 & 0.522 & 0.536 & 80 & 78 \\
\hline 1.6 & 114 & 117 & 54 & 57 & 583 & 616 & 0.510 & 0.524 & 80 & 78 \\
\hline 1.7 & 117 & 120 & 54 & 57 & 583 & 616 & 0.498 & 0.512 & 80 & 78 \\
\hline 1.8 & 120 & 123 & 54 & 57 & 583 & 616 & 0.487 & 0.501 & 80 & 78 \\
\hline 1.9 & 122 & 125 & 54 & 57 & 583 & 616 & 0.477 & 0.491 & 80 & 78 \\
\hline 2.0 & 125 & 128 & 54 & 57 & 583 & 616 & 0.467 & 0.481 & 80 & 78 \\
\hline
\end{tabular}

*Feed intake is calculated based on: a feed with a MElh content of $11.8 \mathrm{MJ} / \mathrm{kg}$, a requirement of $12.1 \mathrm{~kJ}$ per $\mathrm{g}$ egg mass, a maintenance requirement of $435 \mathrm{~kJ} M E$ per $\mathrm{kg} \mathrm{MBW}\left(\mathrm{BW}^{\wedge} 0.75\right)$, a requirement of $21.5 \mathrm{~kJ}$ ME per gram BWG, a daily BWG of $1.5 \mathrm{~g}$, and $9.5 \mathrm{~kJ}$ ME per kg BW per unit decrease in ${ }^{\circ} \mathrm{C}$ below $25^{\circ} \mathrm{C}$ and a daily temperature of $22^{\circ} \mathrm{C}$.

${ }^{* *}$ The optimal SID-VAL:SID-LYS ratio for maximum EM is calculated based on the ratio between SID-VAL intake (SID-VAL requirements calculated based on a requirement of $10.8 \mathrm{mg}$ SID-VAL per $\mathrm{g}$ of egg mass) and SID-LYS intake which is based on formula [F8] described in CVB Documentation report nr. 69.

In Table 4 the estimated optimal SID-VAL requirements for maximum EM are presented based on a SID-VAL requirement that is based on the relationship shown in Figure 1.

Table 4. Estimated optimal SID-VAL requirements for maximum EM expressed in $\mathrm{mg} / \mathrm{d}$ and as a percentage of the diet for maximum EM at various egg production rates based on the relationship shown in Fig. 1. The calculated feed intake required for an average egg weight of $60 \mathrm{~g}$ and at egg production rates of 90 and $95 \%$ are based on the assumptions presented as a footnote $\left({ }^{*}\right)$ underneath this Table.

\begin{tabular}{|c|c|c|c|c|c|c|c|c|c|c|}
\hline \multirow[b]{3}{*}{ BW (kg) } & \multicolumn{2}{|c|}{$\begin{array}{r}\text { Feed intake } \\
(\mathrm{g} / \mathrm{d})\end{array}$} & \multicolumn{2}{|c|}{$\begin{array}{r}\text { Egg mass } \\
(\mathrm{g} / \mathrm{d})\end{array}$} & \multicolumn{2}{|c|}{$\begin{array}{r}\text { SID-VAL } \\
(\mathrm{mg} / \mathrm{d})\end{array}$} & \multicolumn{2}{|c|}{$\begin{array}{r}\text { Dietary SID- } \\
\text { VAL (\%) } \\
\end{array}$} & \multicolumn{2}{|c|}{$\begin{array}{l}\text { SID-VAL:SID- } \\
\text { LYS ratio** }\end{array}$} \\
\hline & \multicolumn{10}{|c|}{ Egg production rate (\%) } \\
\hline & 90 & 95 & 90 & 95 & 90 & 95 & 90 & 95 & 90 & 95 \\
\hline 1.5 & 112 & 115 & 54 & 57 & 514 & 588 & 0.460 & 0.512 & 70 & 74 \\
\hline 1.6 & 114 & 117 & 54 & 57 & 514 & 588 & 0.449 & 0.500 & 70 & 74 \\
\hline 1.7 & 117 & 120 & 54 & 57 & 514 & 588 & 0.439 & 0.489 & 70 & 74 \\
\hline 1.8 & 120 & 123 & 54 & 57 & 514 & 588 & 0.429 & 0.479 & 70 & 74 \\
\hline 1.9 & 122 & 125 & 54 & 57 & 514 & 588 & 0.420 & 0.469 & 70 & 74 \\
\hline 2.0 & 125 & 128 & 54 & 57 & 514 & 588 & 0.411 & 0.459 & 70 & 74 \\
\hline
\end{tabular}

*Feed intake is calculated based on: a feed with a MElh content of $11.8 \mathrm{MJ} / \mathrm{kg}$, a requirement of $12.1 \mathrm{~kJ}$ per $\mathrm{g}$ egg mass, a maintenance requirement of $435 \mathrm{~kJ} M E$ per $\mathrm{kg} \mathrm{MBW}\left(\mathrm{BW}^{\wedge} 0.75\right)$, a requirement of $21.5 \mathrm{~kJ} \mathrm{ME}$ per gram BWG, a daily BWG of $1.5 \mathrm{~g}$, and $9.5 \mathrm{~kJ}$ ME per kg BW per unit decrease in ${ }^{\circ} \mathrm{C}$ below $25{ }^{\circ} \mathrm{C}$ and a daily temperature of $22^{\circ} \mathrm{C}$.

**The optimal SID-VAL:SID-LYS ratio for maximum EM is calculated based on the ratio between SID-VAL intake (SID-VAL requirements calculated based on the relationship shown in Fig. 1) and SID-LYS intake which is based on formula [F8] described in CVB Documentation report nr. 69. 
In Table 5 the estimated optimal SID-VAL requirements for minimum FCR are presented based on SID-VAL requirements that are based on the relationship shown in Figure 2.

Table 5. Estimated optimal SID-VAL requirements for minimum FCR expressed in $\mathrm{mg} / \mathrm{d}$ and as a percentage of the diet for maximum EM at various egg production rates based on the relationship shown in Fig. 2 . The calculated feed intake required for an average egg weight of $60 \mathrm{~g}$ and at egg production rates of 90 and $95 \%$ are based on the assumptions presented as a footnote $\left(^{*}\right)$ underneath this Table.

\begin{tabular}{|c|c|c|c|c|c|c|c|c|c|c|}
\hline \multirow[b]{3}{*}{ BW (kg) } & \multicolumn{2}{|c|}{$\begin{array}{r}\text { Feed intake } \\
(\mathrm{g} / \mathrm{d})\end{array}$} & \multicolumn{2}{|c|}{$\begin{array}{r}\text { Egg mass } \\
(\mathrm{g} / \mathrm{d})\end{array}$} & \multicolumn{2}{|c|}{$\begin{array}{r}\text { SID-VAL } \\
(\mathrm{mg} / \mathrm{d})\end{array}$} & \multicolumn{2}{|c|}{$\begin{array}{r}\text { Dietary SID- } \\
\text { VAL (\%) }\end{array}$} & \multicolumn{2}{|c|}{$\begin{array}{l}\text { SID-VAL:SID- } \\
\text { LYS ratio** }\end{array}$} \\
\hline & \multicolumn{10}{|c|}{ Egg production rate $(\%)$} \\
\hline & 90 & 95 & 90 & 95 & 90 & 95 & 90 & 95 & 90 & 95 \\
\hline 1.5 & 112 & 115 & 54 & 57 & 489 & 543 & 0.438 & 0.473 & 67 & 69 \\
\hline 1.6 & 114 & 117 & 54 & 57 & 476 & 519 & 0.416 & 0.442 & 65 & 66 \\
\hline 1.7 & 117 & 120 & 54 & 57 & 469 & 504 & 0.401 & 0.420 & 64 & 64 \\
\hline 1.8 & 120 & 123 & 54 & 57 & 468 & 496 & 0.391 & 0.404 & 64 & 63 \\
\hline 1.9 & 122 & 125 & 54 & 57 & 470 & 494 & 0.384 & 0.394 & 64 & 62 \\
\hline 2.0 & 125 & 128 & 54 & 57 & 473 & 495 & 0.379 & 0.386 & 65 & 63 \\
\hline
\end{tabular}

*Feed intake is calculated based on: a feed with a MElh content of $11.8 \mathrm{MJ} / \mathrm{kg}$, a requirement of $12.1 \mathrm{~kJ}$ per $\mathrm{g}$ egg mass, a maintenance requirement of $435 \mathrm{~kJ}$ MElh per $\mathrm{kg} \mathrm{MBW}\left(\mathrm{BW}^{\wedge} 0.75\right)$, a requirement of $21.5 \mathrm{~kJ}$ MElh per gram BWG, a daily BWG of $1.5 \mathrm{~g}$, and $9.5 \mathrm{~kJ}$ MElh per kg BW per unit decrease in ${ }^{\circ} \mathrm{C}$ below $25 \stackrel{\circ}{\circ}$ and a daily temperature of $22{ }^{\circ} \mathrm{C}$.

${ }^{* *}$ The optimal SID-VAL:SID-LYS ratio for minimum FCR is calculated based on the ratio between SID-VAL intake (SID-VAL requirements calculated based on the relationship shown in Fig. 2) and SID-LYS intake which is based on formula [F8] described in CVB Documentation report nr. 69.

Summarised, the calculated SID-VAL:SID-LYS ratios presented in Tables $3-5$ vary between $78-69$ for a bird of $1.5 \mathrm{~kg}$ producing an EM of $57 \mathrm{~g} / \mathrm{d}$. These ratios are substantially lower than the average SID-VAL:SID-LYS requirement ratios as shown in Table 2 that vary between 86 and 95. This can be explained by the low dietary SID-LYS concentrations used in the titration trials (average content of $0.578 \%$ ) and the resulting high efficiency in which dietary SID-LYS was converted into egg mass (average ratio of 11.4). This complicates the decision which dietary SID-VAL:SID-LYS ratio should be chosen as the conversion of dietary SID-LYS into egg mass in document TC-CVB-119 (based on a large dataset of SID-LYS titration trials) for a hen producing an egg mass of $57 \mathrm{~g} / \mathrm{d}$ is around $13.9 \mathrm{mg}$ per $\mathrm{g}$ of EM. It seems most logic therefore to express the requirement for SID-VAL per $g$ of EM.

Furthermore, as the estimated SID-VAL requirement per $g$ of EM is higher for maximum EM compared to minimum FCR it seems most safe to base the requirement for SID-VAL on the requirement for maximum EM. 


\section{Conclusions}

It is concluded that the basis for establishing SID-VAL requirements is small. Based on the little information there is it seems that SID-VAL requirements are higher for maximum EM production than for minimum FCR. The in this study established SID-VAL requirement for maximum EM production is $10.8 \mathrm{mg}$ per $\mathrm{g}$ of EM. A SID-VAL supply of $10.8 \mathrm{mg}$ per gram of EM produced combined with a SID-LYS requirement estimated using formula [F8] in CVB documentation report number 69 results in a SID-VAL : SID-LYS requirement ratio of $78 \%$. 


\section{List of studies included in the meta-analysis}

Peganova, S. \& Eder, K. 2002. Studies on requirement and excess of valine in laying hens. Archiv fur Geflugelkunde, 66, 241-250.

\section{References}

Blok, M. C. and R. A. Dekker. 2017. Table 'Standardized ileal digestibility of amino acids in feedstuffs for poultry'. CVB Documentation report nr. 61.

Krimpen, M. M., T. Veldkamp, J. W. van Riel, V. Khaksar, H. Hashemipour, M.C. Blok, and W. Spek. 2015. Estimating requirements for apparent faecal and standardised ileal digestible amino acids in laying hens by a meta-analysis approach.

Robbins, K. R., Saxton, A. M. \& Southern, L. L. 2006. Estimation of nutrient requirements using broken-line regression analysis. Journal of Animal Science, 84, E155-E165.

Spek, J. W. 2018. Standardized ileal digestible lysine requirement for laying hens. CVB Documentation report nr. 69. 


\section{Appendix A. Relationship between dietary SID-VAL supply and performance parameters FCR and EM for the various titration trials including the estimated SID-VAL requirements based on the quadratic broken-line model}

The letter 'a' behind the trial number (shown in the first column) means the model is fitted on all observations except the 2 observations with the highest dietary SID-VAL levels. If no letter is shown behind the trial number it means that the model is fitted based on all observations of the trial.

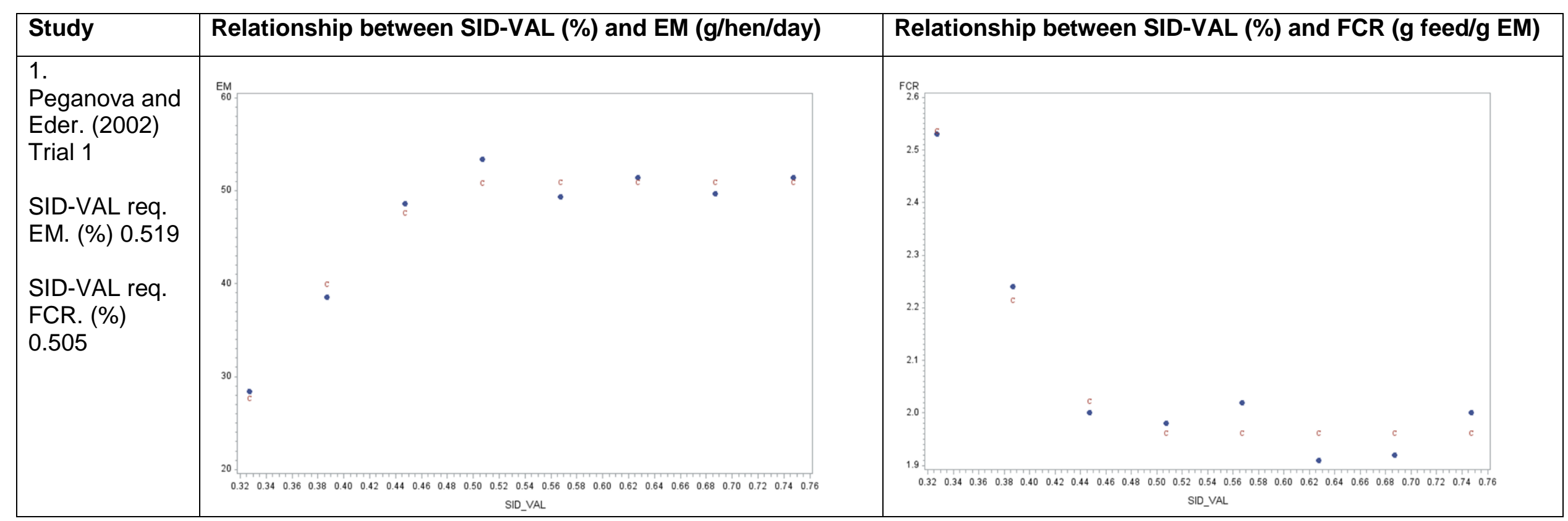




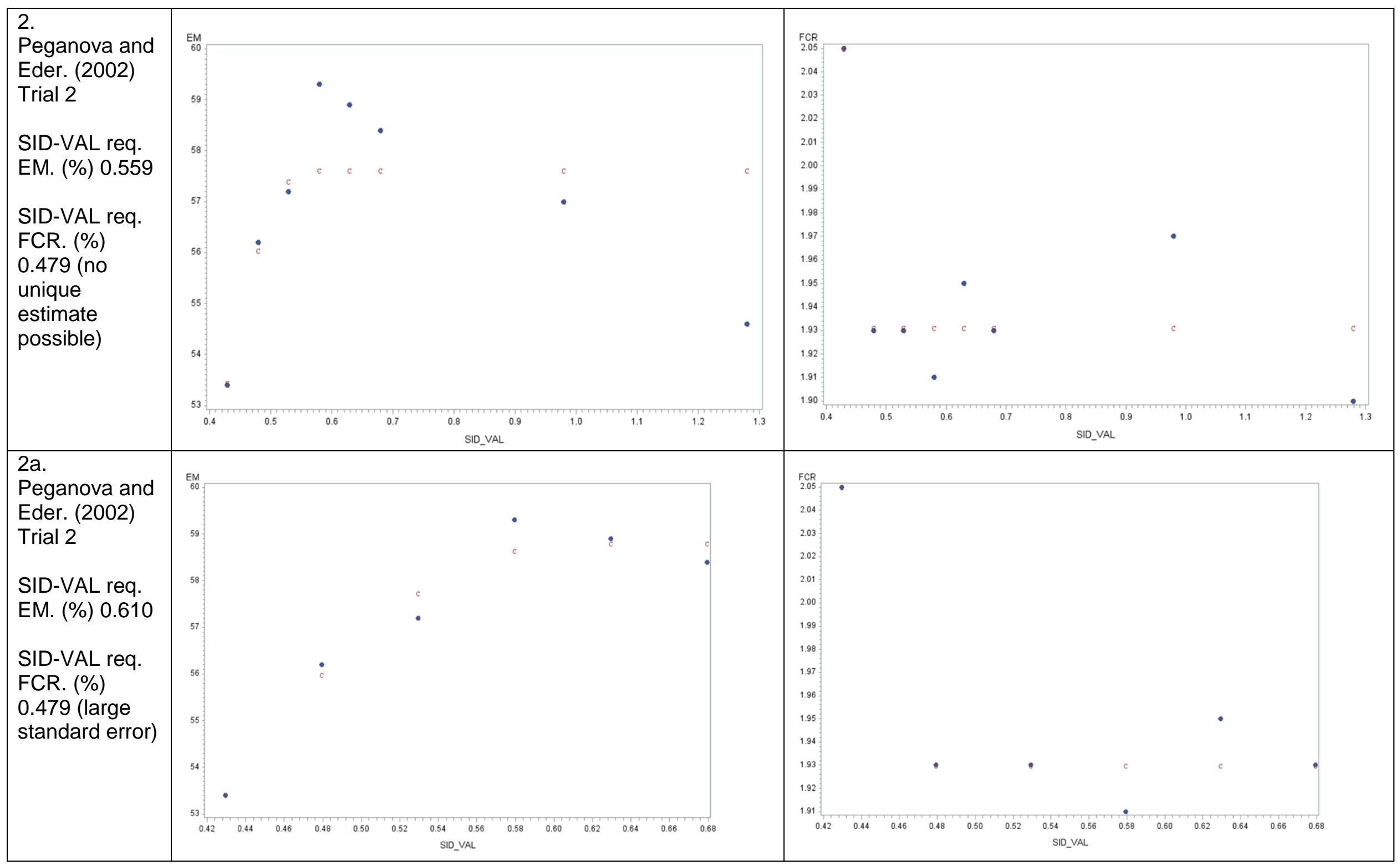

17 


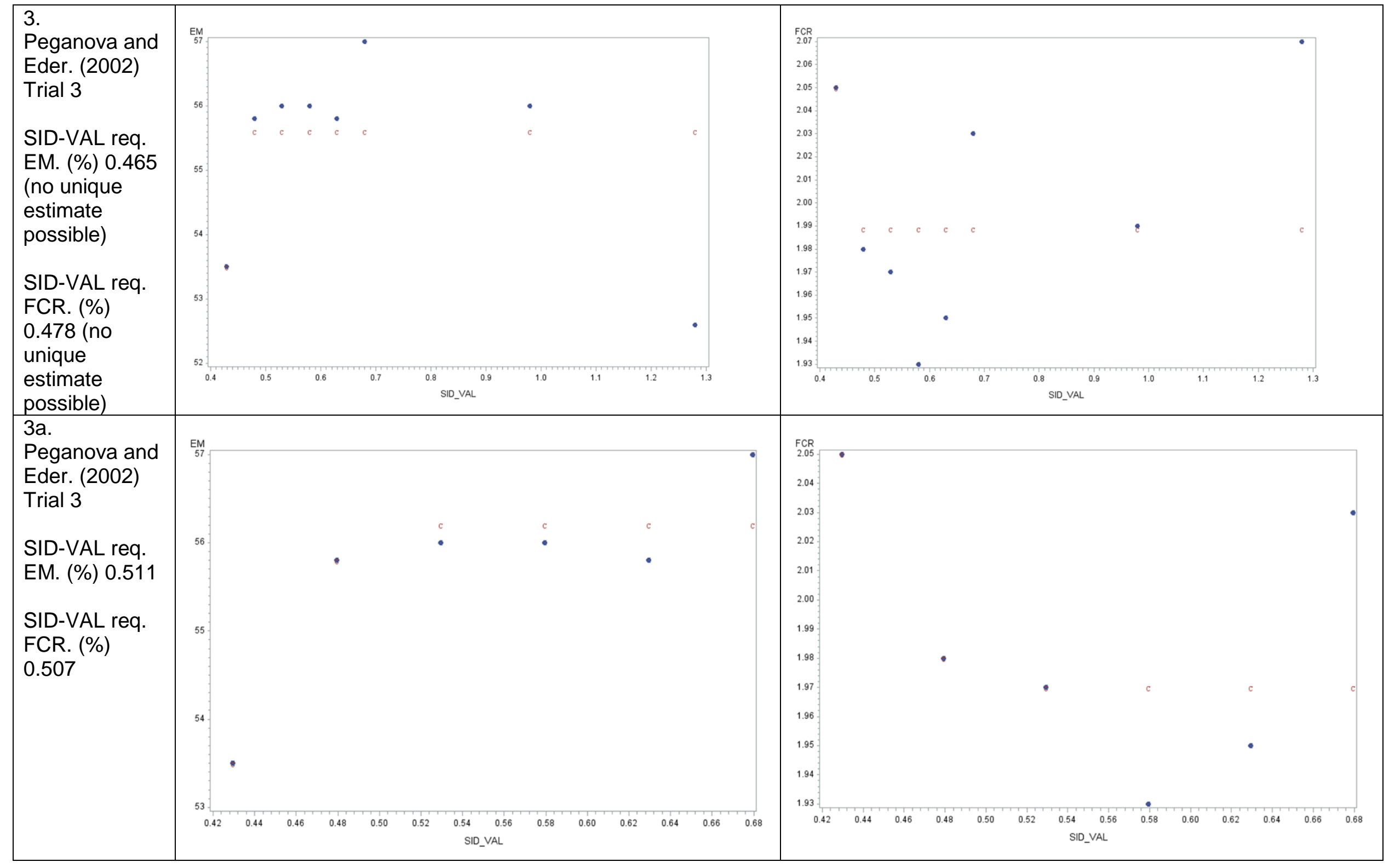




\section{Appendix B. SID-VAL model estimates for minimum FCR and maximum EM}

SID-VAL model estimates for minimum FCR. The estimated $R$ values shown in bold were excluded in the statistical analysis of SID-VAL requirements. The letter 'a' behind the trial number (shown in the first column) means the model is fitted on all observations except the 2 observations with the highest dietary SID-VAL levels. If no letter is shown behind the trial number it means that the model is fitted based on all observations of the trial.

\begin{tabular}{|c|c|c|c|c|c|c|c|}
\hline $\begin{array}{l}\text { Trial } \\
\text { nr. }\end{array}$ & $\begin{array}{r}\text { Estimate } \\
\mathrm{L}\end{array}$ & $\begin{array}{r}\text { Std. Err. } \\
\text { L }\end{array}$ & $\begin{array}{r}\text { Estimate } \\
\mathbf{R} \\
\end{array}$ & $\begin{array}{r}\text { Std. Err. } \\
R\end{array}$ & $\begin{array}{r}\text { Estimate } \\
\mathbf{U}\end{array}$ & $\begin{array}{r}\text { Std. Err. } \\
\text { U }\end{array}$ & $\mathbf{R}^{2}$ \\
\hline & 1.96 & 0.021 & 0.505 & 0.0268 & -18 & 6 & 0.965 \\
\hline & 1.9 & 0.009 & 0.479 & & -47 & 10 & 0.789 \\
\hline $2 a$ & 1.9 & 0.008 & 0.479 & 6.0483 & -48 & 11589 & 0.938 \\
\hline 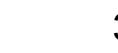 & 1.99 & 0.018 & 0.478 & & -26 & 22 & 0.194 \\
\hline $3 a$ & 1.97 & 0.022 & 0.507 & 0.1004 & -13 & 35 & 0.479 \\
\hline
\end{tabular}

SID-VAL model estimates for maximum EM. The estimated $R$ values shown in bold were excluded in the statistical analysis of SID-VAL requirements. The letter 'a' behind the trial number (shown in the first column) means the model is fitted on all observations except the 2 observations with the highest dietary SID-VAL levels. If no letter is shown behind the trial number it means that the model is fitted based on all observations of the trial.

\begin{tabular}{|c|c|c|c|c|c|c|c|}
\hline $\begin{array}{l}\text { Trial } \\
\text { nr. }\end{array}$ & $\begin{array}{r}\text { Estimate } \\
\text { L }\end{array}$ & $\begin{array}{r}\text { Std. Err. } \\
\text { L }\end{array}$ & $\begin{array}{r}\text { Estimate } \\
\mathbf{R}\end{array}$ & $\begin{array}{r}\text { Std. Err. } \\
\mathbf{R}\end{array}$ & $\begin{array}{r}\text { Estimate } \\
\mathrm{U}\end{array}$ & $\begin{array}{r}\text { Std. Err. } \\
\text { U }\end{array}$ & $\mathbf{R}^{2}$ \\
\hline 1 & 51 & 0.8 & 0.519 & 0.0264 & 632 & 186 & 0.971 \\
\hline 2 & 58 & 0.8 & 0.559 & 0.1040 & 249 & 426 & 0.514 \\
\hline $2 a$ & 59 & 0.4 & 0.610 & 0.0370 & 166 & 70 & 0.962 \\
\hline 3 & 56 & 0.5 & 0.465 & & 1652 & 1166 & 0.251 \\
\hline $3 a$ & 56 & 0.3 & 0.511 & 0.0378 & 409 & 386 & 0.869 \\
\hline
\end{tabular}

